\title{
Moisture monitoring of stone masonry: A comparison of microwave and radar on a granite wall and a sandstone tower
}

\author{
Scott Allan Orr ${ }^{\mathrm{b}, \mathrm{a}, *}$, Lucie Fusade ${ }^{\mathrm{b}}$, Maureen Young ${ }^{\mathrm{c}}$, Dawson Stelfox ${ }^{\mathrm{d}}$, Alick Leslie ${ }^{\mathrm{e}, \mathrm{f}}$, \\ Joanne Curran ${ }^{\mathrm{d}}$, Heather Viles ${ }^{\mathrm{b}}$ \\ a UCL Institute for Sustainable Heritage, University College London, Central House, 14 Upper Woburn Pl, WC1H 0NN London, United Kingdom \\ b School of Geography and the Environment, University of Oxford, South Parks Road, Oxford OX1 3QY, United Kingdom \\ ${ }^{\mathrm{c}}$ Historic Environment Scotland, The Engine Shed, Stirling, Forthside Way, Stirling FK8 1QZ, United Kingdom \\ d Consarc Design Group, The Gas Office, 4 Cromac Quay, Ormeau Road, Belfast BT7 2JD, United Kingdom \\ e Formerly Historic Environment Scotland, United Kingdom \\ ${ }^{\mathrm{f}}$ The Getty Conservation Institute, 1200 Getty Center Dr no. 700, Los Angeles, CA 90049, USA
}

\section{N F O A R T I C L E}

\section{Historique de l'article :}

Reçu le 11 décembre 2018

Accepté le 16 juillet 2019

Disponible sur Internet le xxx

\section{Keywords:}

Non-destructive testing

Water

Data handling

Visual representation

Surveying

Wind-driven rain

\begin{abstract}
A B S T R A C T
Water is a fundamental control on the deterioration of historic stone masonry, of which wind-driven rain (WDR) is an important source in the UK. Non-destructive testing methods for moisture measurement can characterise the response of masonry to short (but intense) periods of wind-driven rain. An important part of this response is how masonry functions as a system of stone units and mortar joints, in which mortar can act as a conduit for moisture. While non-destructive techniques are common in moisture surveying of built heritage, there are no agreed best practice methods for collection, handling, and visual representation of data. This study explores the comparative advantages of microwave and radar measurements in two field experiments of exposure to short (but intense) simulated wind-driven rain exposure to demonstrate when and how they are most effectively employed. A novel method of representing data as percentiles is explored to facilitate effective communication of moisture measurements. In the case of the granite wall (e.g. with components of strongly contrasting hygric properties), microwave and radar provided similar information. The average travel time of the radar signal (from the back wall reflection) demonstrated that radar can non-destructively identify water penetration through mortar joints. In the sandstone tower, the microwave measurements were able to clearly identify four different moisture regimes as a result of different intensities of WDR exposure. The radar measurements were suited to identifying distinctions between localised moisture contents within masonry units and mortar joints, which characterised how the masonry was functioning as a holistic system. The measurements on both the granite wall and the sandstone tower demonstrated that the radar is influenced by environmental conditions which influence surface condensation and equilibrium moisture contents. Representing the measurements as percentiles improved visual representation of measurements with colour scales and minimised potential skewing of normalisation and scales from extreme values/outliers. This paper demonstrates that both microwave and radar techniques can be useful for monitoring moisture in stone masonry systems. Material characteristics of the masonry system and the objective(s) of the investigation should be considered during selection of the appropriate technique(s).
\end{abstract}

(c) 2019 Les Auteurs. Publié par Elsevier Masson SAS. Cet article est publié en Open Access sous licence CC BY (http://creativecommons.org/licenses/by/4.0/).

\section{Introduction}

Stone-built masonry walls, of simple composition, are routinely found in many historic cities and sites and can be prone to problems with structural stability, energy losses and moisture ingress.

* Corresponding author at: UCL Institute for Sustainable Heritage, University College London, Central House, 14 Upper Woburn Pl, WC1H 0NN London, United Kingdom.

Adresse e-mail : scott.orr@ouce.ox.ac.uk (S.A. Orr).
Recent research has addressed their characteristics and behaviour using a range of non-destructive and invasive test methods. Granite walls in Porto have been studied to characterise their strength before and after injection with lime mortar [1], whilst in Slovenia, an array of in situ tests have been employed to explore the structural stability of a selection of important historic sites dominated by masonry walls [2]. Building on research on $U$ values in a range of brick structures, the thermal performance of a range of historic rubble masonry walls made of sedimentary building stones in northern Italy have been explored [3]. 
Table 1

Experimental design of simulated WDR exposure to compare microwave and radar moisture measurement techniques.

\begin{tabular}{|c|c|c|c|c|}
\hline $\begin{array}{l}\text { Experiment } \\
\text { site }\end{array}$ & Construction materials & Situation & Study area & Measurement spacing \\
\hline Oxford & $\begin{array}{l}\text { Granite and natural } \\
\text { hydraulic lime }(\mathrm{NHL}) \\
\text { lime mortar }\end{array}$ & $\begin{array}{l}\text { Behaviour of masonry (units and } \\
\text { joints) with strongly contrasting } \\
\text { hygric properties }\end{array}$ & $55 \mathrm{~cm} \times 55 \mathrm{~cm}$ & $\begin{array}{l}5 \mathrm{~cm} \text { grid (radar), } 5 \mathrm{~cm} \text { point } \\
\text { spacing (microwave sensor) }\end{array}$ \\
\hline \multicolumn{5}{|l|}{ Edinburgh } \\
\hline Scenario A & $\begin{array}{l}\text { Sandstone and NHL } \\
\text { lime mortar }\end{array}$ & $\begin{array}{l}\text { Behaviour of masonry (units and } \\
\text { joints) with more similar hygric } \\
\text { properties; four intensities of WDR } \\
\text { spells }\end{array}$ & $\begin{array}{l}80 \mathrm{~cm} \times 80 \mathrm{~cm} \text {, including four } \\
\text { zones of } 30 \mathrm{~cm} \times 30 \mathrm{~cm}\end{array}$ & $\begin{array}{l}5 \mathrm{~cm} \text { grid (radar), } 10 \mathrm{~cm} \text { point } \\
\text { spacing (microwave sensor) }\end{array}$ \\
\hline Scenario B & $\begin{array}{l}\text { Sandstone, NHL lime } \\
\text { mortar but with } \\
\text { existing fragments of } \\
\text { mortar of unknown } \\
\text { composition }\end{array}$ & $\begin{array}{l}\text { Behaviour of masonry (units and } \\
\text { joints) with more similar hygric } \\
\text { properties; behaviour of mortar } \\
\text { joints in managing heavy WDR } \\
\text { intensity }\end{array}$ & $\begin{array}{l}80 \mathrm{~cm} \times 80 \mathrm{~cm} \text {, including four } \\
\text { zones of } 30 \mathrm{~cm} \times 30 \mathrm{~cm}\end{array}$ & $\begin{array}{l}5 \mathrm{~cm} \text { grid (radar), } 10 \mathrm{~cm} \text { point } \\
\text { spacing (microwave sensor) }\end{array}$ \\
\hline
\end{tabular}

Water is an integral component of direct and indirect weathering processes of historic building materials such as stone, which can cause deterioration of masonry [4]. Wind-driven rain (WDR) is a significant source of moisture for buildings in the UK and other parts of Northern Europe [5, pp. 14-15], exposure to which is expected to become more severe and seasonally polarised over the 21 st century as a result of climate change [6], including short-term events.

Non-destructive techniques can be an important part of managing moisture in built cultural heritage. These are indirect, non-invasive methods that use physical properties as proxies for the presence of water on and within porous building materials. The spatial capture/resolution and measurement principle of a technique determine how and when it is best applied in monitoring moisture regimes.

A common approach is to monitor humidity (atmospheric moisture in the vapour phase) by measuring relative humidity. This is frequently done by embedding probes within constructions [7-9] for long-term monitoring. The use of embedded sensors into the wall to measure the temperature and relative humidity can give accurate measurement of the area but are also subject to failure [10]. Since these probes are embedded within a construction, they are not entirely non-destructive.

The monitoring of liquid water is more commonly surveyed quickly, and without the use of embedded probes. This is commonly used to identify sources of ingress as part of a building pathology approach [11]. Previous research has assessed the liquid moisture content of mortar joints using brick test walls using visual assessment and weight [12]. The visual assessment is limited to penetration of water through walls that can be observed, while the total weight provides limited information about the distribution of water across a façade.

Non-destructive techniques for moisture measurement on masonry and mortar joints include infrared thermography (IRT) and electrical resistivity tomography (ERT). Infrared thermography is a common technique to assess the thermal performance of masonry-for example, it can be a powerful tool when combined with the hot box technique [13]. It can be also be used as an indication of moisture [14], although this is primarily limited to near-surface conditions. IRT is often not precise [14,15] but gives a good overview of the masonry moisture pattern. ERT is affected by the presence of salt due to its impact on conductivity [7] and requires different calibration for stone and mortars [16]. Therefore, research using a similar technique that can assess both surface and depth conditions that is independent of salinity in stone units and mortar joints is needed. Radar and ERT have been used to analyse the localised moisture contents of mortar joints and masonry units, but is often analysed visually [17], despite the quantitative potential of these techniques that has been demonstrated on other building materials [18,19]. A multi-sensor approach has been shown to be particularly useful for natural stone [16].

How data from a moisture survey is handled and visually represented depends on the objectives of the investigation. Representing data over space and/or time are two common forms of presentation; however, these aspects of communicating results are not formalised or explored widely in the current state-of-the-art of measuring moisture in buildings and building materials [20-22].

Moisture-sensitive non-destructive methods are typically used to characterise the relative distribution of liquid water across an entire façade [23]. The unique systemic qualities of stone masonry (units and joints) has either been considered negligible, i.e. measurements are interpolated across joints and masonry units (e.g. [24-26]) or the joints are omitted from the survey, i.e. measurements are taken on individual masonry units alone [16]. This disregards the potential benefit of capitalising on the spatial geometries of non-destructive techniques to assess the dynamic behaviour of masonry systems, as represented by interactions between masonry units and joints.

\section{Research aim}

The primary aim of this study is to evaluate the performance of microwave sensors and radar for monitoring the movement of water in masonry constructions exposed to wind-driven rain. To evaluate this, scenarios of simulated short (but intense) winddriven spells are developed for two objects of study: a purpose-built wall of Cornish granite and lime mortar, and part of New College, Edinburgh, United Kingdom. The latter is a nineteenth century sandstone tower that has been exposed to approximately 150 years of moisture-related weathering. A comparison of the spatial and temporal dynamics of the drying of these two constructions aims to enable a discussion of their comparative advantages for characterising the behaviour of masonry systems exposed to wind-driven rain. The benefits and trade-offs of a proposed new method of representing measurements as percentiles are explored, as well as the combined benefit of using temporal and spatial graphical representation forms.

\section{Material and methods}

\subsection{Experimental design}

To assess the response of the masonry constructions to short (but intense) wind-driven rain spells realistic characteristics of rain (amount and intensity) and wind (speed and direction) were simulated in two field experiments (Table 1). The methodology is 

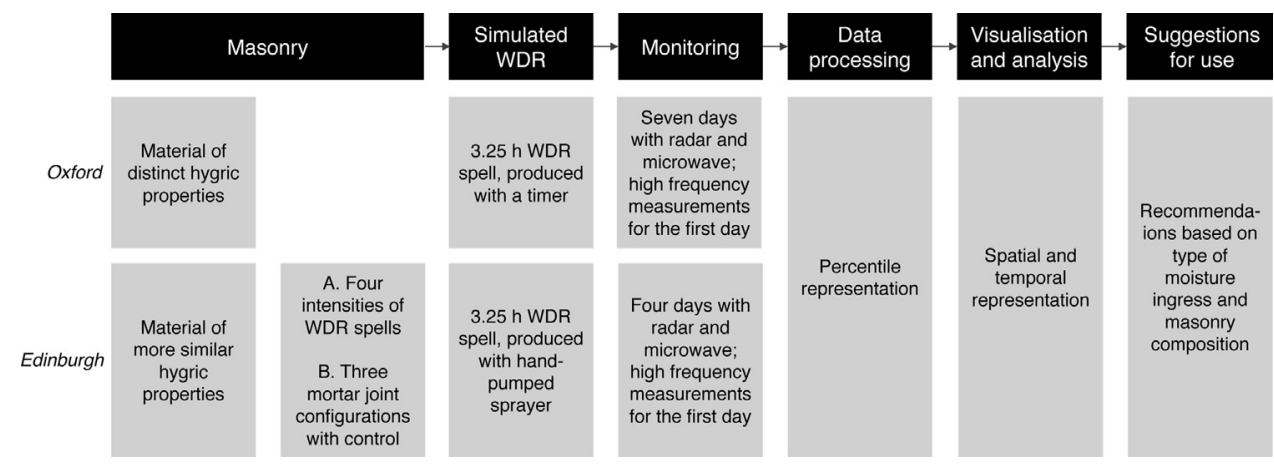

Fig. 1. An overview of the methodology, specifying similar and contrasting components between Oxford and Edinburgh experiments.

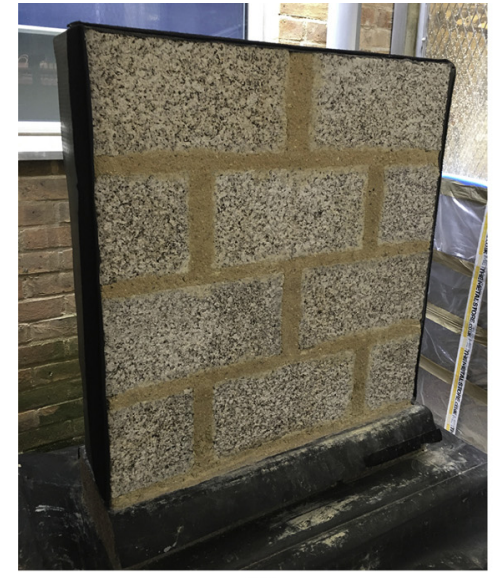

(a)

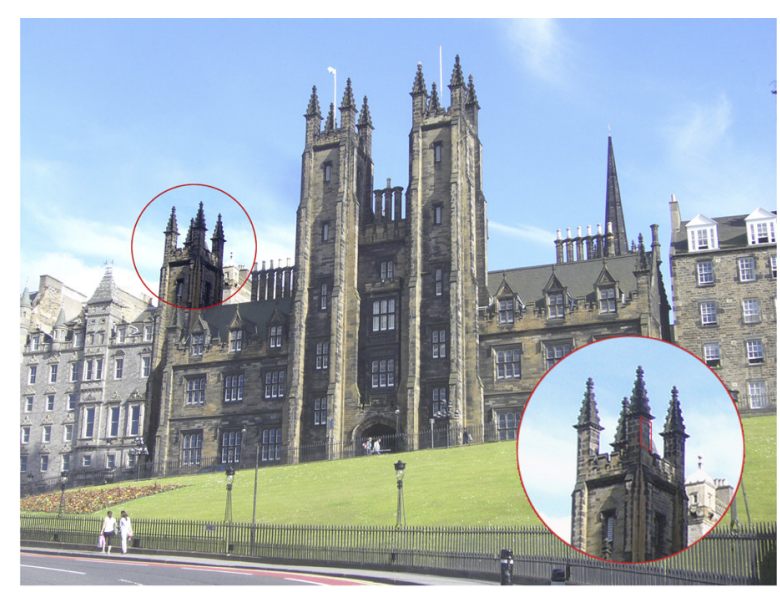

(b)

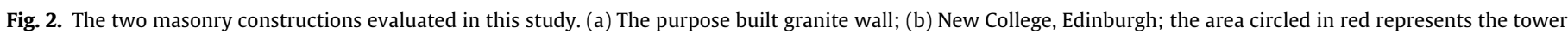
on which evaluations were undertaken. The latter is adapted from 'New College on the Mound, Edinburgh' by Kim Traynor, Wikimedia, CC BY-SA 3.0.

summarised in Fig. 1. Microwave sensors and radar were used to record moisture levels before and following the simulated winddriven rain. The first experiment focused on a purpose-built test wall of granite masonry units located in Oxford, UK designed to reflect the wealth of built heritage in southwest England where very low porosity masonry units (e.g. granite) are surrounded by much more porous mortar joints and exposed to high amounts of driving rain. In this scenario, the mortar joints should experience high rates of moisture penetration. The second field experiment focused on the base of a pinnacle of a nineteenth century tower in Edinburgh constructed from sandstone which has experienced moisture-related weathering for over 150 years. This was accessed with scaffolding during a conservation project.

Both experiments are representative of conditions in regions in the UK that currently experience high wind-driven rain exposure [27] and are expected to suffer intensified WDR by the end of the 21 st century [6]. The experiments were designed to simulate characteristic durations and volumes of water in intense WDR events. The volume and duration of wind-driven rain applied was determined using a semi-empirical representation of WDR spells [28] based on hourly meteorological data obtained from the UK Met Office for a site in Devon $(51.0886,-4.14743)$ from 2005 to 2015 [29,30]. Devon was selected as buildings in this region are often comprised of impervious granite and receive high amounts of WDR exposure [31].

It is important to note that the semi-empirical representation of WDR used in ISO 15927 [28] has been shown to not always accurately represent the amount of wind-driven rain that is impacting a surface [32], due to sheltering and the complex geometries common in the built environment. However, the ISO formula has been shown to reasonably represent the modelled amount of winddriven rain impacting the southwest façade of a highly-exposed tower [33], which is similar in context to the Edinburgh case study. In this way, the WDR exposure quantity used here is intended to represent highly-exposed built contexts, such as towers, for which this is a small expected impact of local factors such as topography and other buildings.

Recent work has demonstrated inaccuracies in a percentilebased approach when estimating extreme WDR events [34]. For this reason, extreme value analysis [34,35], in combination with the Gumbel distribution, was applied to thirty years of wind-driven rain spells (lasting $5 \mathrm{~h}$ or less) derived from ISO 15927 [28] for the aforementioned site in Devon. The most severe WDR spell within this duration range likely to occur once in any five-year period for a south-westerly oriented wall was $10.32 \mathrm{~L} \mathrm{~m}^{-2}$. Similar short (but intense) spells have also been recorded in eastern Scotland. This exposure quantity was used to as a guideline for the simulated exposure, and was distributed over $3 \mathrm{~h}$ to represent the mid-range of spell durations used to determine this intensity.

\subsection{Oxford experiment: purpose-built granite test wall}

A purpose-built test wall of granite and natural hydraulic lime (NHL) lime mortar was constructed outside in a sheltered area in central Oxford to test the behaviour of masonry (units and joints) with strongly contrasting hygric properties. A light grey Cornish granite with an open porosity of $0.87 \pm 0.05 \%$ was used; the lime mortar used NHL 3.5 and had equal ratios of quartz and calcitic sand aggregate with an open porosity of $20.33 \pm 0.21$ [36]. The test wall is $660 \mathrm{~mm}$ high, $620 \mathrm{~mm}$ wide and $150 \mathrm{~mm}$ thick and constructed 


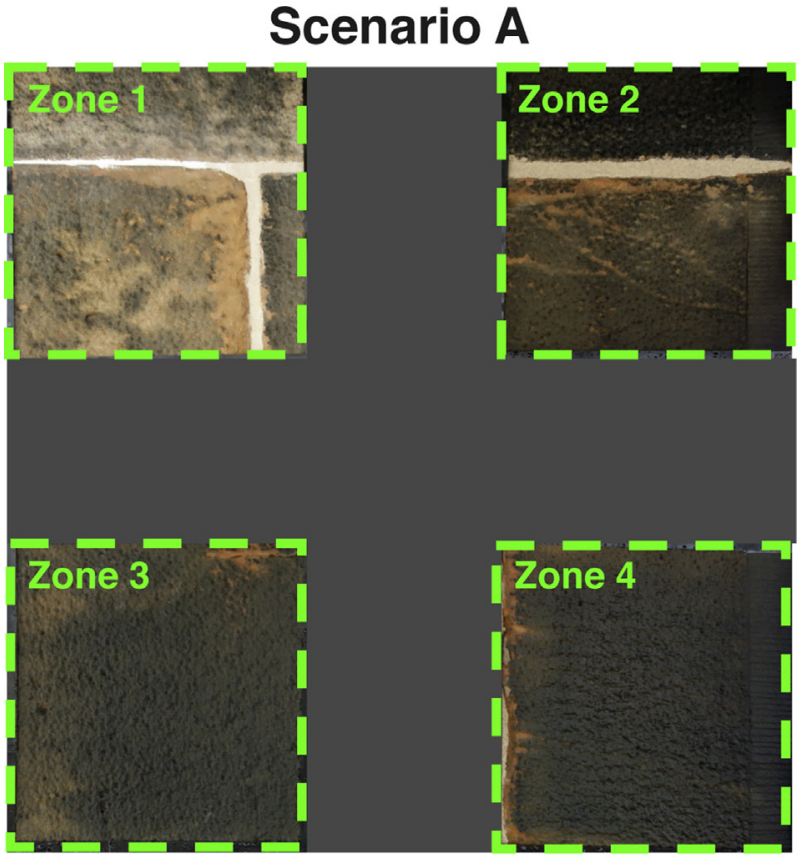

\section{Scenario B}

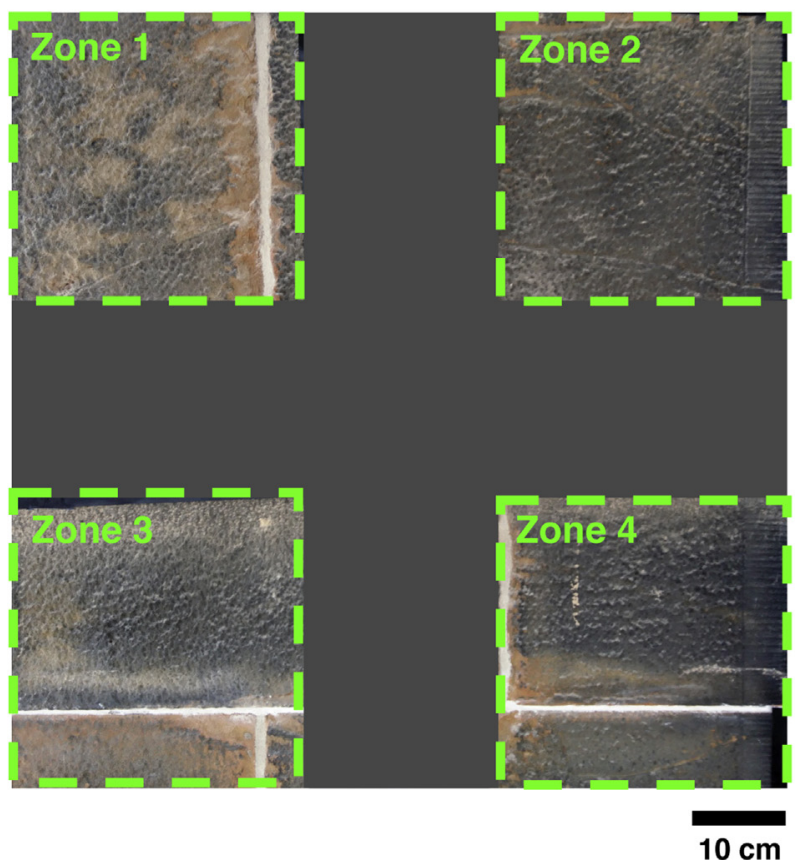

Fig. 3. The measurement areas for the Edinburgh experiment, demonstrating the four zones in Scenario A and Scenario B. The cream-coloured/lighter portions are mortar joints and orange and blackened regions are the masonry units. The grey 'cross' represents 'no data' because of an impervious barrier applied directly to the façade surface between the zones which remained on the surface for the duration of the monitored drying.

out of Cornish granite blocks with a pointed dressing (see Fig. 2). The units are embedded with joints approximately $2 \mathrm{~cm}$ wide of an NHL 3.5 lime mortar produced with quartz sand and calcitic aggregate. After construction, the wall was left to cure in ambient spring conditions in Oxford, UK for approximately 90 days. The wall was constructed and cured under a cover to minimise the impact of precipitation during curing and testing.

On the granite test wall, WDR was simulated using tap water applied through a full cone low-flow nozzle with a uniform spray distribution. Within the range of spell durations used within the extreme value analysis (see Section 3.1) to determine exposure guidelines ( 1 to $5 \mathrm{~h}$ ), a spell duration of $3.25 \mathrm{~h}$ (with $15 \mathrm{~s}$ of simulated WDR every $3 \mathrm{~min}$ ) resulted in a total of $10.35 \mathrm{~L} \mathrm{~m}^{-2}$ of simulated WDR on the test wall façade [36]. This produced the nearest value of WDR exposure to the target exposure of $10.32 \mathrm{~L} \mathrm{~m}^{-2}$.

\subsection{Edinburgh experiment: New College, Edinburgh}

Two scenarios were executed in the Edinburgh experiment, to evaluate the behaviour of masonry composed of units and joints with similar hygric properties. In Scenario A, three different levels of WDR intensity were simulated, while Scenario B evaluated the role of mortar joints in managing heavy WDR intensity (see Fig. 3 and Table 1). Both scenarios included a control region comprised of masonry units and mortar units without WDR exposure.

New College (see Fig. 2) is located in central Edinburgh, Scotland. It is the University of Edinburgh's School of Divinity, the current building of which was constructed in 1846 [37] primarily in Binny Sandstone; Binny is a Lower Carboniferous sandstone from Scotland [38]. Despite Edinburgh's proximity to Britain's east coast, prevailing winds originate from the southwest [39]. The eastern Scottish climate is characterised by moderate to heavy annual rainfall distributed throughout the year. New College is situated on an exposed site on the south side of the crag and tail formation crowned by Edinburgh Castle. This results in increased intensity and quantity of wind-driven rain.

During the experiments, the New College building was undergoing stone replacement and mortar repointing due to significant moisture-related weathering. Wind-driven rain simulations were carried out on a pinnacle of the west tower, due to its exposed location relative to other parts of the building. The pinnacle is composed of large masonry units ( $30 \mathrm{~cm}$ in their shortest dimension), and had been partially repointed with an NHL lime mortar shortly before the experiments commenced. Some joints were not repointed; the pre-existing mortar is of an unknown composition and age.

During testing the pinnacle was sheltered from direct solar irradiation and rainfall by plastic netting installed for the maintenance and restoration work. WDR was simulated with a backpack sprayer pressurised to 2 bar with a hand-pump, which delivered water with a low through-put full-cone brass nozzle. The objectives of each scenario necessitated different configurations of WDR exposure and mortar joints (Table 2). The zones were studied simultaneously, to reduce the potential impact on environmental variability of rates of absorption and evaporation. To enable this, an impervious layer was applied to the surface during simulated WDR to minimise the potential for the exposure of one zone to influence another. The zones of the façade were selected to be sufficiently near to one another to have negligible differences in environmental conditions, while also be measurable in a single radar grid scan. This layer was left on the surface throughout the duration of the monitored drying to inhibit surface evaporation from these faces, thereby further reducing inter-zonal interference due to sub-surface migration.

\subsubsection{Monitoring}

In both experiments, measurements were taken before the simulated WDR exposure and repeated at intervals afterwards. Measurements were taken at 5 or $10 \mathrm{~cm}$ grid/point spacing (see Table 1) with a microwave moisture device and a high resolution radar. Both techniques are non-invasive and have negligible influence from salinity due to their operating frequencies. For the Edinburgh experiment, measurements were also taken at hourly intervals during the simulated WDR spell to monitor moisture ingress. Temperature and relative humidity of the local environment and close to the masonry surface were recorded with iButtons hygrochrones and a weather station (Vaisala, Vantaa, FI). 
Table 2

Experimental design of the two scenarios designed for simulated WDR exposure of the sandstone tower.

\begin{tabular}{|c|c|c|c|c|c|}
\hline Scenario & Motivation & Zone & Joints & WDR classification & $\begin{array}{l}\text { WDR quantity (over } \\
3 \mathrm{~h} \text { ) } \\
\mathrm{L} \mathrm{m}^{-2}\end{array}$ \\
\hline \multirow{4}{*}{ A } & $\begin{array}{l}\text { Investigation of four intensities } \\
\text { of WDR spells }\end{array}$ & 1 & horizontal and vertical & control & 0 \\
\hline & & 2 & horizontal & light & 2.5 \\
\hline & & 3 & None & medium & 5.0 \\
\hline & & 4 & None & heavy & 10 \\
\hline \multirow{4}{*}{ B } & $\begin{array}{l}\text { Investigation of different } \\
\text { mortar joint configurations }\end{array}$ & 1 & vertical & control & 0 \\
\hline & & 2 & none & heavy & 10 \\
\hline & & 3 & vertical and horizontal & heavy & 10 \\
\hline & & 4 & horizontal & heavy & 10 \\
\hline
\end{tabular}

MOIST350B. Produced by hf sensor, Leipzig, DE: the MOIST350B is a device that produces microwave fields of varying geometry sensitive to different depths [40,41]. The recorded reflection values are based on average properties within the measurement area, but with decreasing sensitivity to moisture further away from the sensor (i.e. the surface). An important result of this is that measurements may represent the presence of moisture up to a depth that is a fraction of sensor's total depth of penetration. The sensors have been found to calibrate well over a range of water contents for building stones [27]. Two sensors were employed: one penetrating up to $2-3 \mathrm{~cm}$ (R1M) and another up to $20-30 \mathrm{~cm}$ (PM).

High resolution radar. Produced by Malå Geosciences, Malå, SE: a radar signal is produced by a $1.6 \mathrm{GHz}$ antenna coupled with a receiver that measures the travel time of the signal. Changes in material properties cause large reflections within the signal [42]. The travel time between reflections can be converted into an average velocity for a particular point within a construction, which under certain assumptions can be used to calculate the dielectric constant: a physical property that is strongly influenced by water content [43]. Additionally, the amplitude of the surface (direct) wave is strongly dependent on water content and can be used as a proxy for near-surface water contents [44]. Both radar characteristics have been shown to calibrate well over a range of moisture contents for porous building materials [27] and are investigated here.

\subsection{Percentile representation of measurements}

How moisture measurement data are handled and visually represented is primarily driven by: (1) the spatial and temporal scale(s) used, and (2) the survey aim(s). Spatially, most applications of non-destructive techniques to monitor moisture have been at a façade (several $\mathrm{m}^{2}$ ) scale, e.g. [26]. In these cases, the visualisation typically uses a scale of colour/shade (i.e. heat map) based on a uniform distribution to represent variation of moisture levels. While this can be useful for communicating moisture distributions, colour scales are one of the least accurately used graphical forms $[45,46]$. Mapping non-uniformly distributed measurements onto a uniformly-distributed colour scale reduces the graphical resolution. This is especially apparent when measurements are skewed, e.g. if measurements are polarised to extremes. This skew also affects scatter plots of measurements over time, since a linear X-axis scale is typically used.

To improve upon this aspect of visual representation measurements can be converted to percentiles. A percentile is assigned to each measurement by ranking them in order of magnitude, from which a fraction or percentage of values for which a number is greater can be determined (the percentile). Representing measurements with percentiles has several benefits, including:
- equal resolution across the range of measurement values, regardless of the distribution, e.g. they will not be impacted by clusters or polarised data;

- reduced impact of extreme values/outliers on normalisation or scale limits;

- colour bins can be assigned to equally-sized percentile ranges, i.e. each colour represents an equal fraction of all measurements within the set

The same percentiles can be used in other, more accurately used, forms of graphical representations, e.g. those based on positions with common aligned scales, such as multiple bar charts or box plots with a single scale [47], facilitating comparison between multiple visual representation formats of moisture measurements.

In this study both measurement principles are proportional to water contents, i.e. higher percentiles imply higher moisture levels. The percentile for each measurement has been determined from all measurements taken over the spatial and temporal range of each experiment/scenario. Since the measured variables have different units and ranges, the percentile representations have been compared to values normalised between 0 and 1 . These visualisations are provided in the Supplementary Information, and referred to at the relevant points in the text. As this normalisation would not impact the distribution of the measurement data, it can be used to evaluate how percentile representation changes the data visualisation, while also enabling comparison between different techniques and variables. Normalised values have been used in NDT applications, especially for evaluating multiple techniques/variables (e.g. [48]).

\section{Results}

This study explores the application of microwave and radar measurements in two types of constructions: a granite wall and a sandstone tower. Benefits and trade-offs of spatial and temporal graphical forms and percentile representation in each situation are discussed.

\subsection{Oxford experiment}

\subsubsection{Comparison of microwave and radar: masonry with} strongly contrasting component physical properties

The experiment on the granite wall demonstrates that the microwave near-surface sensor (R1M) and the radar direct (surface) wave amplitude produce similar data in this scenario. Despite using percentile representation, the spatial colour plots (Fig. 4) have limited utility due to the high visual contrast between the granite and joints.

While a general comparison of moisture levels is possible, e.g. by $168 \mathrm{~h}$ the microwave measurements (Fig. 4a,c) indicate more water has left joints towards the top of the wall than the bottom, 
Before simulated WDR

(a) Surface microwave sensor (R1M)

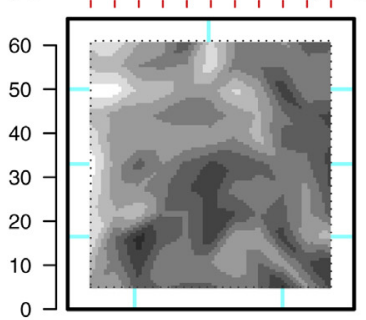

(b) Radar direct wave amplitude

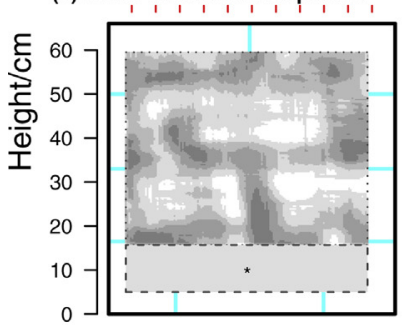

(c) Depth microwave sensor (PM)

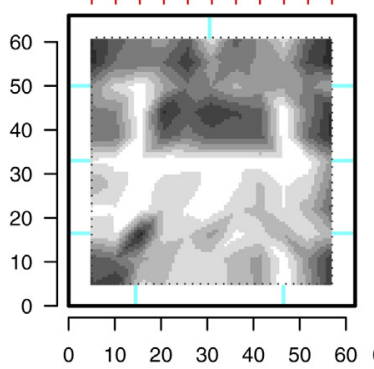

Unmeasurable due to spatial constraint oh
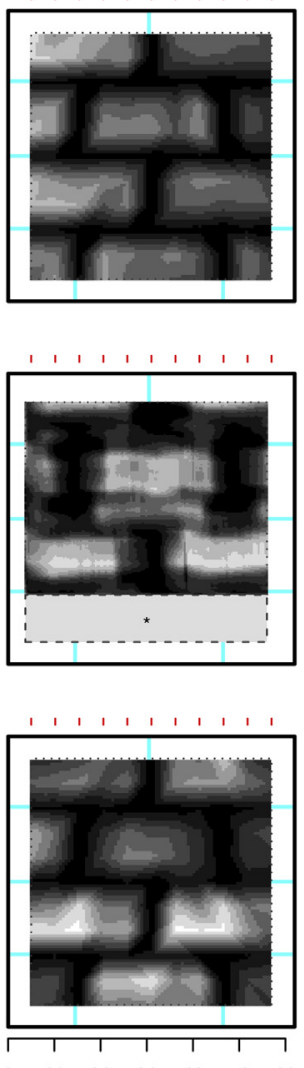

$24 \mathrm{~h}$
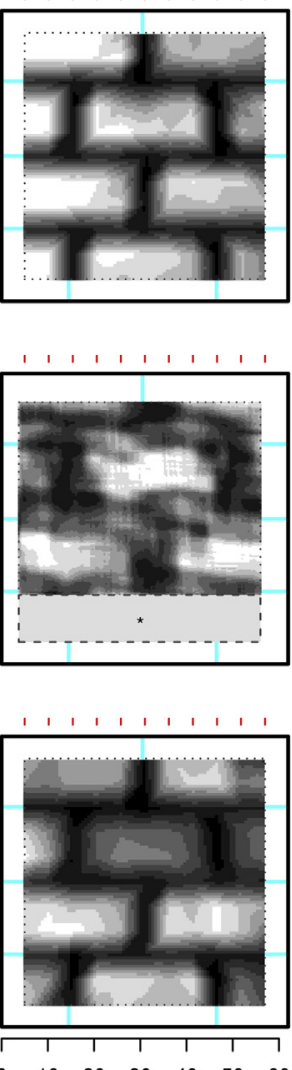

Width/cm
$168 \mathrm{~h}$
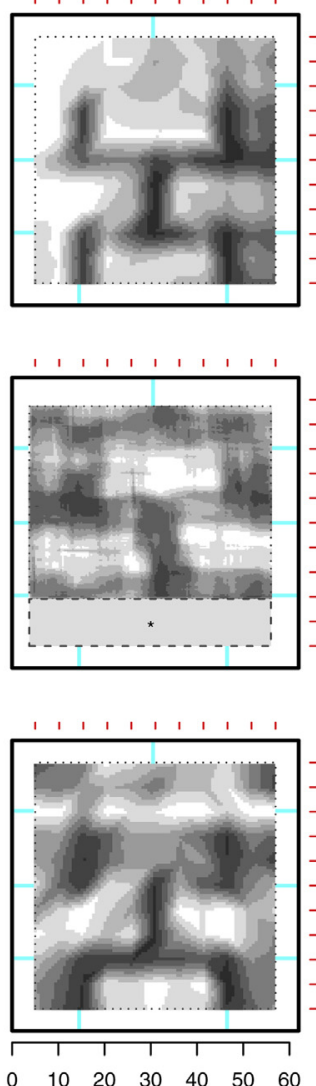

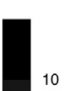

30

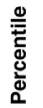

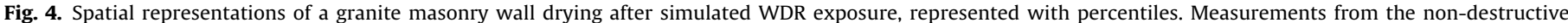

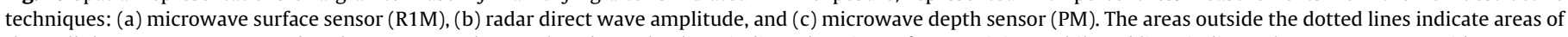
the wall that were not measured as they were too close to the edges. Blue lines indicate locations of mortar joints, while red lines indicate the measurement grid.

shown by the lighter shading here, these spatial representations do not provide information on rates of moisture loss over time or comparisons of water contents of specific joints. However, spatial plots based on normalised measurements provide less information on localised variation than percentile representation due to an even greater polarisation between the granite and joints (Supplementary Information, Figure 1).

Representing the measurements for regions of interest over time in barplots allows for quantitative and semi-quantitative comparison (Fig. 5). Several observations are made:

- The surface microwave sensor (R1M) and the radar direct wave amplitude provide similar information (Fig. 5b,c), e.g. the moisture levels over time exhibit similar behaviour.

- The radar direct wave amplitude is more affected than the microwave sensors by environmental conditions (Fig. 5a,c), e.g. responses to temperature and air humidity influencing surface condensation can be observed in the moisture levels.

- A similar influence of environmental conditions is observed on the surface microwave sensor (R1M) on the granite units (Fig. 5a,b), suggesting that microwave measurements are also affected by surface condensate but dominated by liquid water in the joints.

- The depth microwave sensor (PM) shows that the granite, as expected, absorbs very little water, as the moisture percentile of the median/mean are consistent over the duration of the experiment (Fig. 5d).

- The similarity between the surface and depth microwave sensors (Fig. 5b,d) demonstrates the cumulative nature of the sensors, i.e. they measure to a depth, not at at depth (with decreasing sensitivity); in this way, the depth sensor is influenced by nearsurface water contents.

- Both microwave and radar measurements indicate vertical joints are wetter than horizontal ones (as represented by measurement percentiles, Fig. 5b-d)), likely due to prolonged contact while water runs over their surfaces.

The radar direct wave amplitude is more sensitive than the surface microwave sensor to changes in material properties. This is apparent in the outline of higher percentiles visible in the radar scan (Fig. 4b, before simulated WDR) around mortar joints within the wall (c.f. the R1M measurements in Fig. 4a which is a more homogenous blur). This is also represented in Fig. 5b,c, by a greater difference between percentiles for joints and granite before simulated WDR. However, it should be noted that the granite percentiles are skewed (overestimated) in Fig. 4. This is due to a greater number of a granite measurements than vertical/horizontal joints. In a scenario with significantly different numbers of measurements between subsets (i.e. regions of interest), representation with normalised values (or raw measurements) is preferred (Supplementary Information, Figure 2). Normalised value representation demonstrates that the granite measurements 


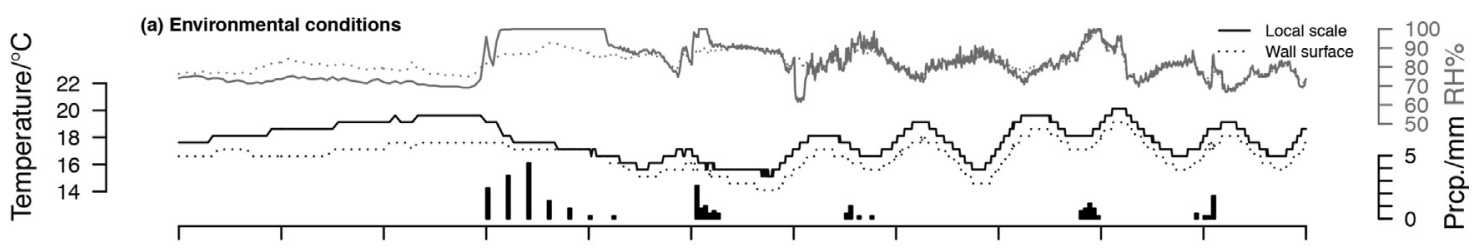

(b) Surface microwave sensor (R1M)
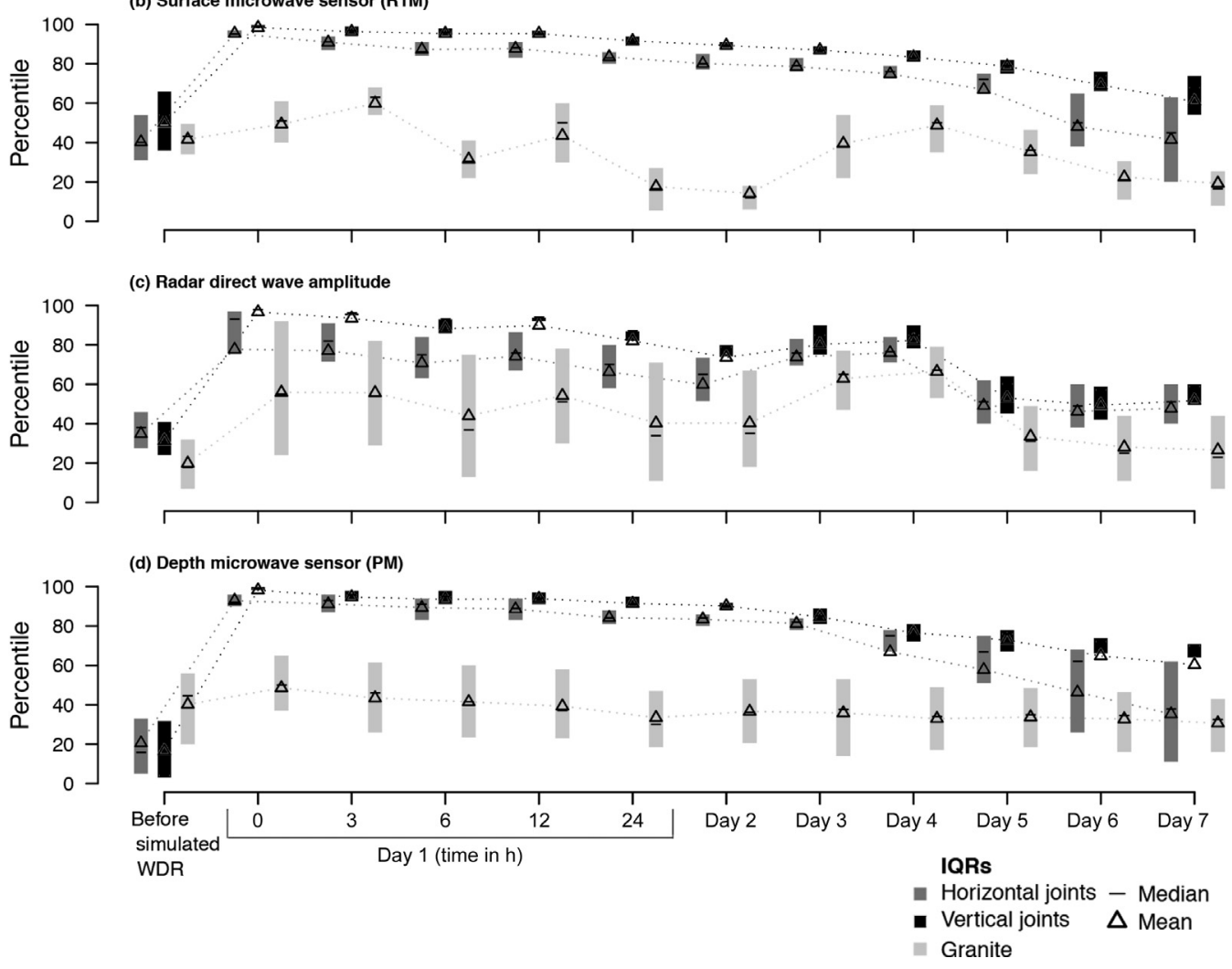

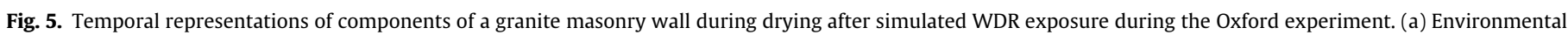
conditions, (b) surface microwave sensor (R1M), (c) Radar direct wave amplitude, and (d) Depth microwave sensor (PM).

are significantly lower than the surrounding mortar joints, which is not reflected in percentile representation due to skew caused by subgroup sizes.

The measurements suggest that the walls are transitioning between Stage I and Stage II drying [49,50] around $96 \mathrm{~h}$ after drying commenced (Fig. 5). This provides validity for the moisture measurements since it conforms to theory. Stage I behaviour occurs when limited evaporation rates manifest as a brief period of pseudo steady-state drying during which there is a constant flux of water out of the surface [51]; in contrast, Stage II drying is characterised by steeper moisture gradients at greater depths [52, p. 205]. The transition is marked by the end of plateaus and increasing slopes in the surface values (R1M and radar direct wave amplitude). It is interesting to note that during Stage II drying the horizontal joints have a higher rate of moisture loss than their vertical counterparts. This could suggest a cycle of moisture movement within the joints: during WDR exposure the vertical joints have a greater uptake, after which the evaporation rates from both are pseudo-steady state, until Stage II drying commences and higher evaporation rates are observed from horizontal joints. Similar performance of horizontal (bed) joints has been observed in measurements and modelled hygric responses of simple representations of masonry systems [53].

\subsubsection{Identifying penetration through mortar joints using radar travel time}

The penetration of liquid water through mortar joints can be identified with radar signal travel time, an additional variable to the direct wave amplitude. This evaluation is possible when the signal penetrates to the back wall and produces a detectable reflection.

Penetration through mortar joints is especially important to consider in constructions such as the granite test wall, in which the mortar joints have a higher moisture burden than joints would if surrounding more porous stone units. As demonstrated in Fig. 6c, visual inspection of the back face of the granite test wall reveals water penetration through the upper joints. This is also observed in total radar travel time (Fig. 6b).

The spatial representation of the depth microwave sensor (PM) is a logical comparison, since it should also detect moisture at depth. The measurement percentiles for this technique (Fig. 6a, also presented in Fig. 4c) demonstrate higher implied water contents in the masonry joints, but it is important to note that microwave sensitivity moisture decreases as a function of depth [43], so these measurements are especially influenced by surface moisture. In contrast, the radar travel time is equally sensitive across the entire profile of the wall, since it is an average travel time across the depth of the masonry. Radar travel time is an effective assessment technique that allows water penetration through joints to be visualised. 
Before simulated WDR

(a) Depth microwave sensor (PM)

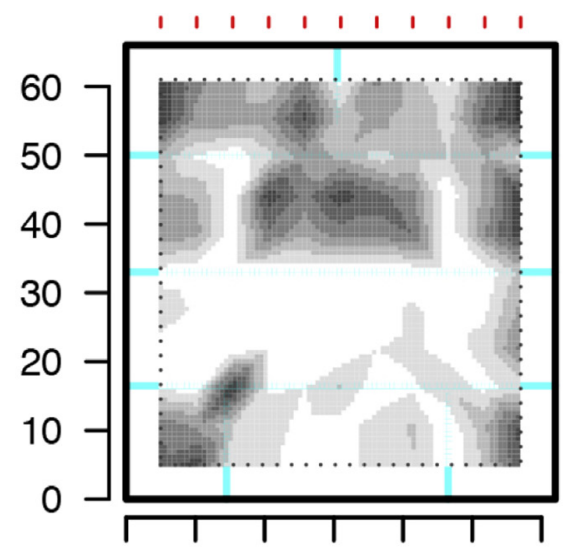

(b) Radar travel time (from back wall reflection)
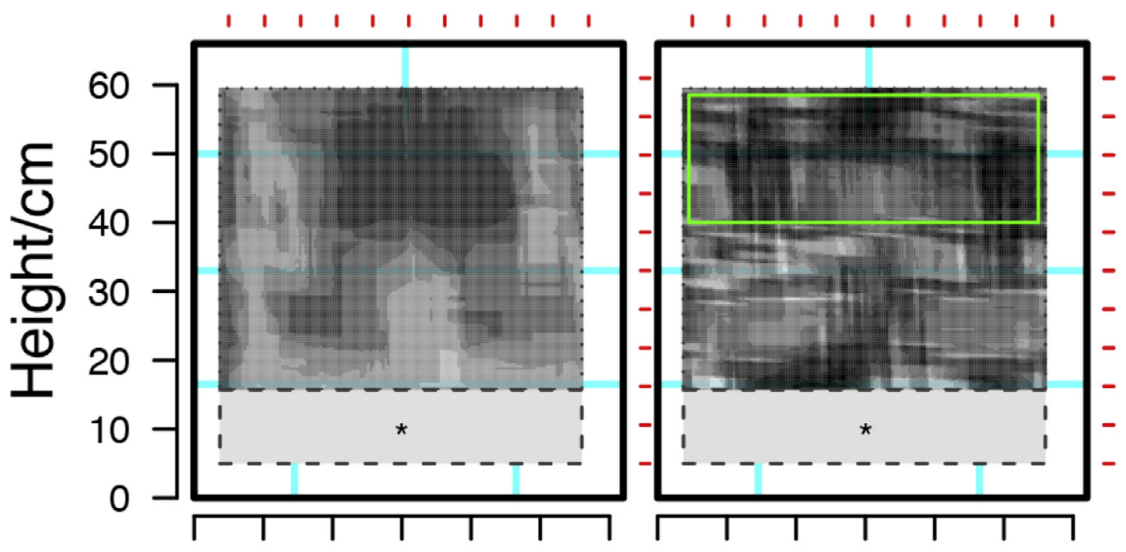

(c) Visual image of back of test wall

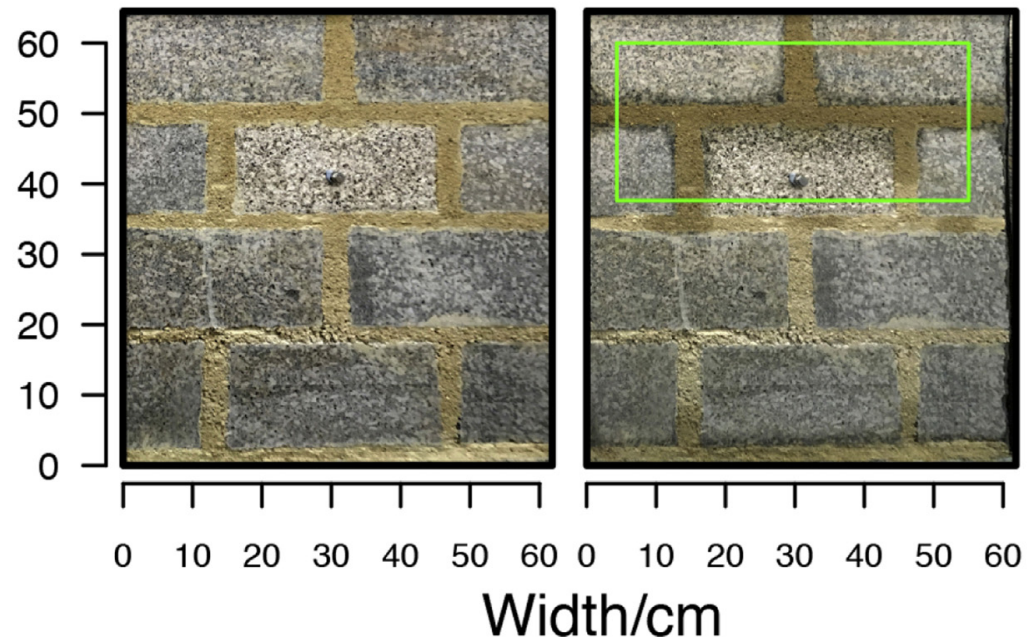

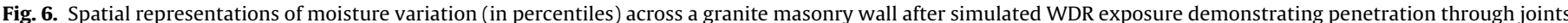

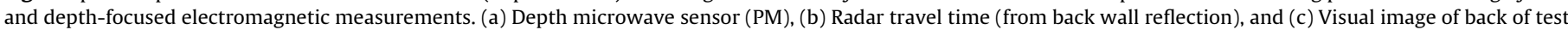

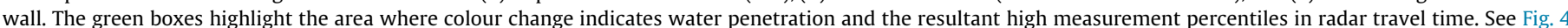

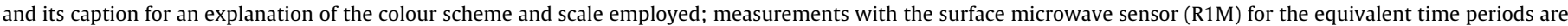
also presented.

\subsection{Edinburgh experiment}

\subsubsection{Comparison of microwave and radar: masonry with similar} component physical properties

Scenario A produced four different intensities of WDR exposure. This demonstrated that the microwave sensors distinguished four distinct 'zones' of moisture levels resulting from four levels of WDR exposure (Figs. 7a,c and 8b,d). The radar direct wave amplitude exhibits more complex behaviour (Figs. 7b and 8c).

The microwave sensor data demonstrates expected Stage I and Stage II drying (refer to Section 4.1.1 for explanation), with surface migration of water. Fig. 8b,d illustrates that the microwave sensor 
Before simulated WDR (a) Surface microwave sensor (R1M)

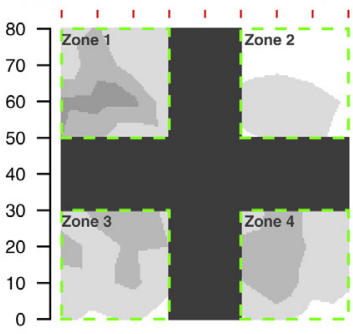

(b) Radar direct wave amplitude

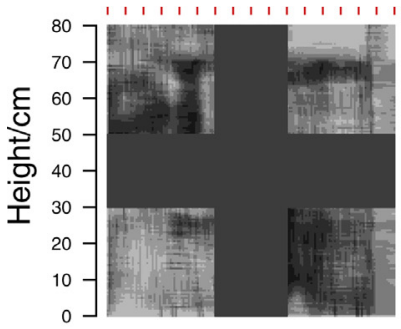

(c) Depth microwave sensor (PM)

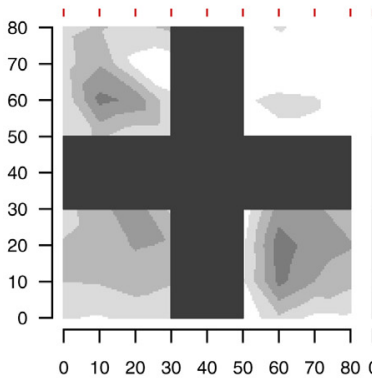

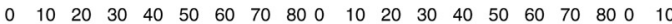

$24 \mathrm{~h}$
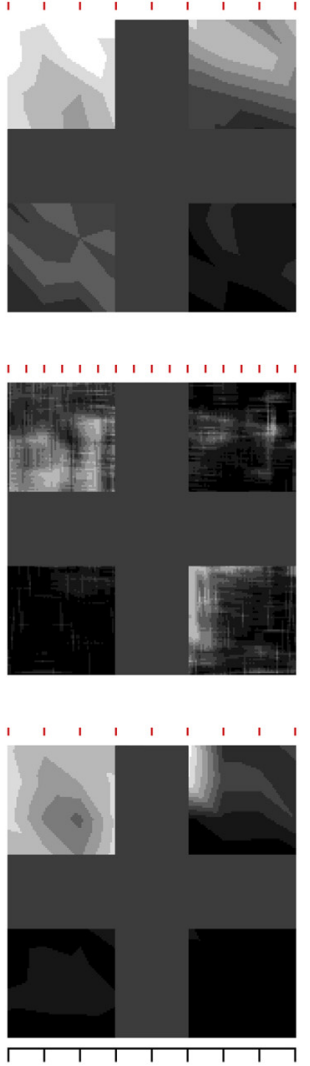
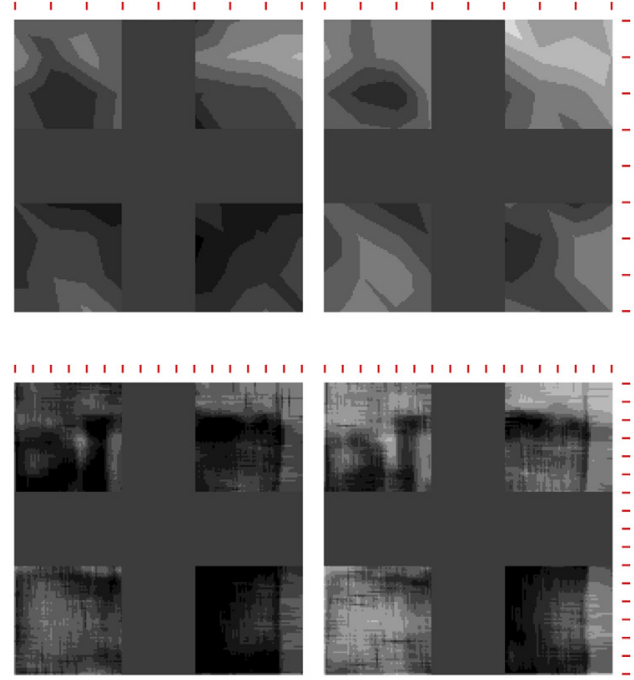

30

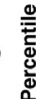
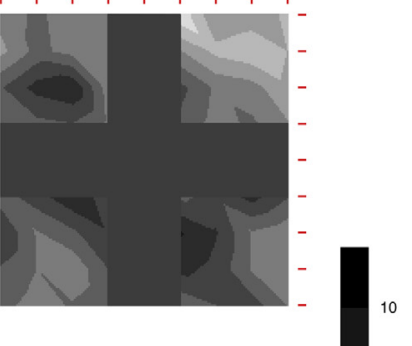

Width/cm

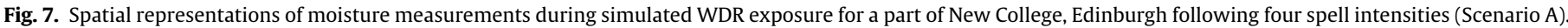

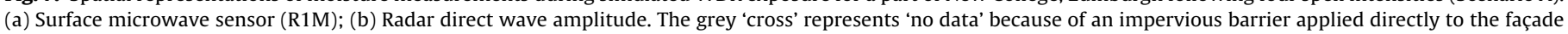
surface between the zones which remained on the surface for the duration of the monitored drying.

measurements are similar between the four zones before the simulated WDR. During the $3 \mathrm{~h}$ spell, microwave measurements with the PM sensor, indicative of water contents at depth, increase rapidly in all zones except Zone 1 which did not receive any direct WDR exposure. During the spell, the surface microwave measurements were noticeably banded in the four zones; after the simulated WDR, the surface moisture levels homogenised to values above the 80th percentile after approximately $3 \mathrm{~h}$ of drying. However, they maintained the order of average moisture levels observed in each zone immediately following the end of simulated WDR. This homogenisation of surface microwave measurements was likely encouraged by moisture migration beneath the impervious barrier between the zones and in response to increased near-surface humidity.

In Scenario A, the radar direct wave amplitude measurements were similar to those of the depth microwave sensor. This contrasts the trends identified for the granite test wall (Oxford experiment), in which changes in surface measurements with environmental conditions were identified in both radar and microwave sensors. This suggests that the direct wave amplitude is sensitive to water contents up to a depth somewhere in between that of the surface and depth microwave sensors. As such, it will exhibit properties more similar to one or the other depending on the moisture regime. The direct wave represents electromagnetic energy transmitted directly to the receiving antenna, as opposed to being a reflection from sub-surface changes in material properties [54]. It is difficult to contextualise the radar direct wave amplitude in twostage drying as no radar-based depth measurement was available for comparison. This is because the back wall reflection was not detectable. In Scenario A of the Edinburgh experiment, the percentiles are less affected by skew (as observed in the Oxford experiment) since they are comprised of equal number of measurements.

\subsubsection{Assessing localised water contents of masonry units and mortar joints}

Scenario B of the Edinburgh experiment examined the role of different mortar joint configurations in the response to heavy WDR exposure. The results demonstrated that both microwave sensors and the radar direct wave amplitude were able to detect differences in water contents between masonry units and mortar joints in a sandstone and lime mortar construction (Fig. 9). However, the radar direct wave amplitude demonstrated a more significant contrast between the percentiles of masonry units and joints, enabling distinction between their hygric response.

The zones exhibited behaviour captured in both microwave and the radar measurements that can be rationalised by their joint configurations. As presented in Fig. 9, Zone 1 (control) had low percentiles and comparable values between the units and the joints. Zone 2 (no joints) exhibited the highest percentiles within the stone units of the four zones. In contrast, Zone 3 (both a horizontal and vertical joint) had lower percentiles within the masonry units and the highest values of any zone within the joints. The percentiles of masonry units and mortar joints were very similar in Zone 4 (only a horizontal joint), emphasising the observations drawn from the 


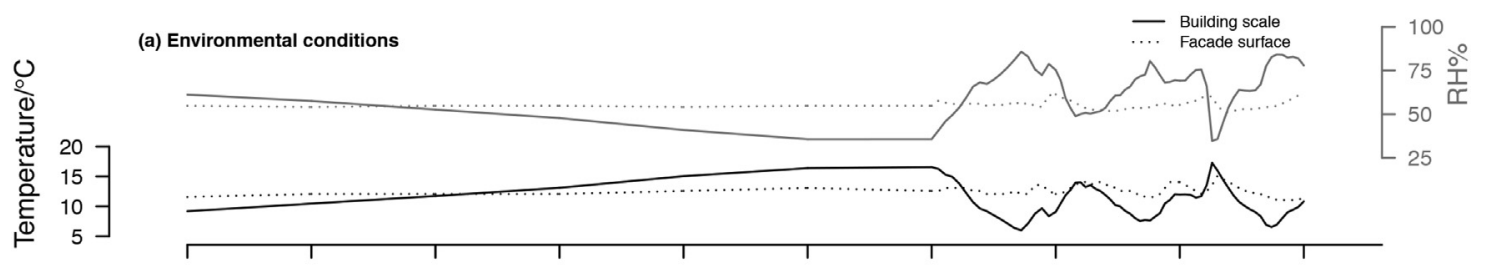

(b) Surface microwave sensor (R1M)

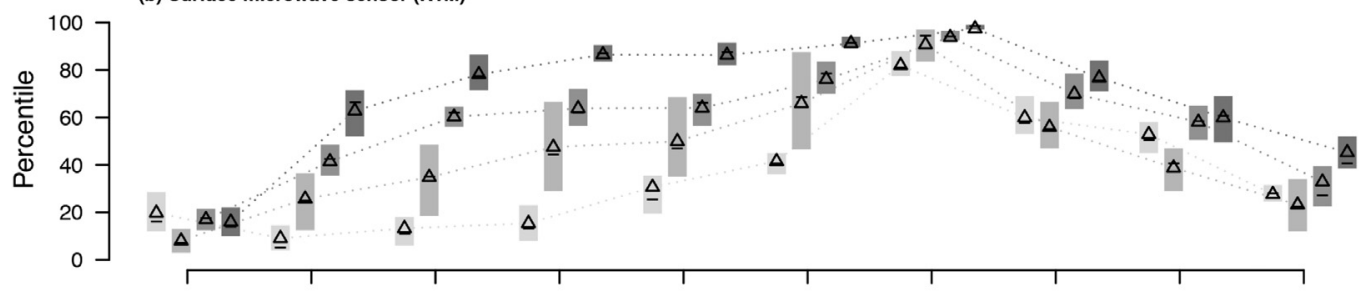

(c) Radar direct wave amplitude

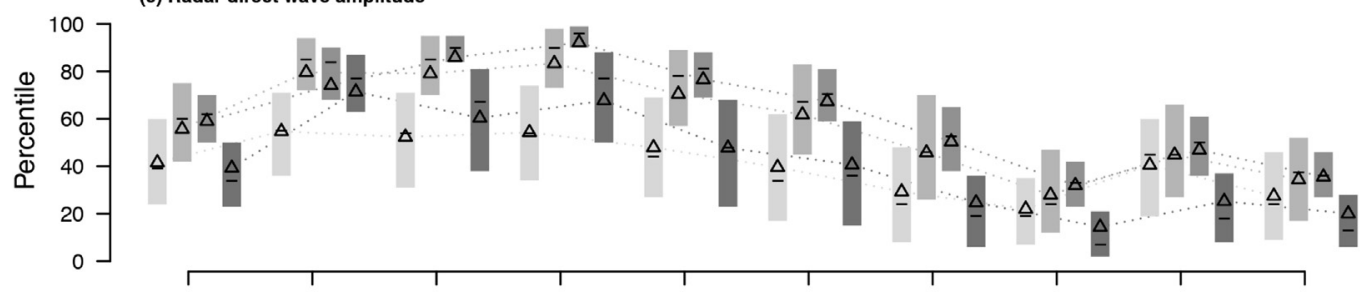

(d) Depth microwave sensor (PM)

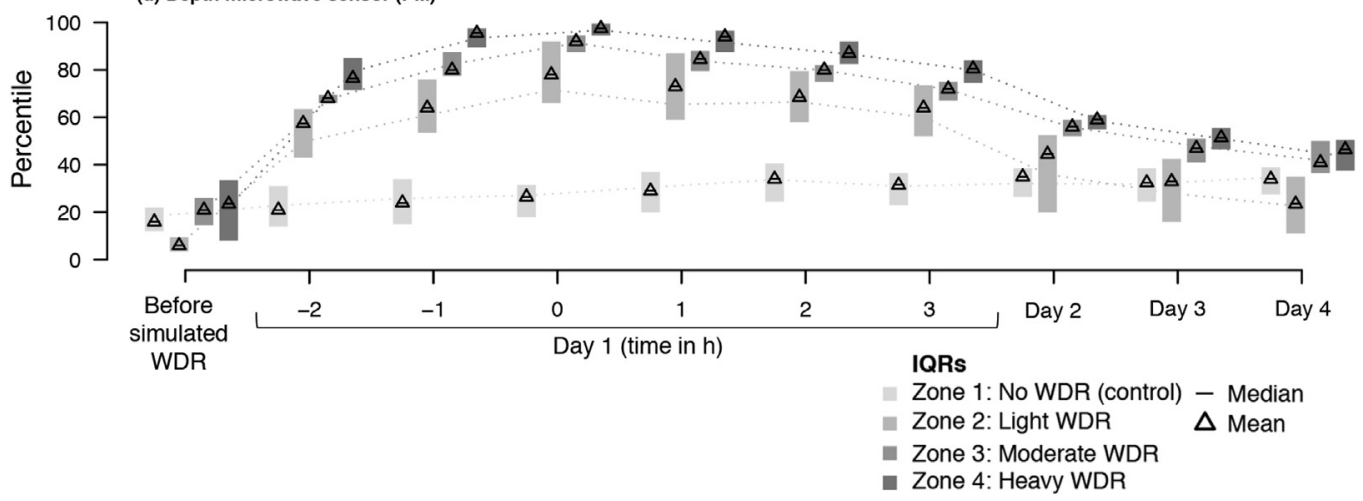

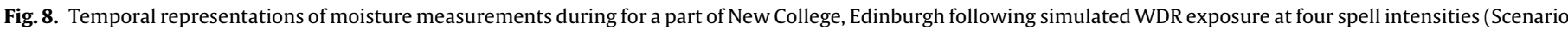

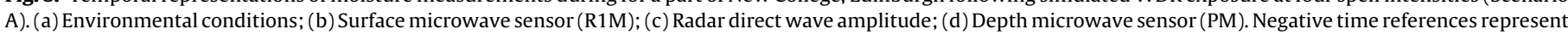
hours within the spell ( $t=0$ is the beginning of the drying process). No precipitation was measured on site during the study time period.

granite test wall of the dominance of vertical joints with respect to moisture uptake.

Fig. 9 demonstrates that the microwave sensors are very sensitive to changes in liquid water contents. This is represented by increases in percentiles from before simulated WDR to the first hour of the simulated spell of at least approximately $60 \%$ regardless of zone. This significant increase reduces the effectiveness of the temporal representation for distinguishing between measurement percentiles of the masonry units and the mortar joints. In contrast, the radar direct wave amplitude exhibits a higher contrast between the joints and the masonry units in Zones 2 to 4 . In this scenario, the percentile skew caused by higher numbers of measurements taken on the masonry units would have been significantly outweighed by the skew introduced by an extreme value in the surface microwave sensor (R1M) data set (Supplementary Information, Figure 3 ); this type of problem is unavoidable without manual cleaning of data for outliers and extreme values, which is based on a subjective evaluation of measurement validity.

Scenario B further supports the theory that the radar direct wave amplitude is influenced by environmental conditions resulting in surface condensation. In the days before the measurements for
Scenario B there had been heavy precipitation; although this did not impact directly on the façade, it affected local climate. Additionally, it is possible that the radar direct wave amplitude percentiles are higher before simulated WDR than for the microwave sensors as the surface water contents are fluctuating in response to condensate induced by higher values of relative humidity early mornings when each scenario began, whereas measurements on subsequent days were taken later in the day.

\section{Discussion}

\subsection{Comparative advantages of radar and microwave techniques}

Both microwave and radar methods can be a part of informative moisture monitoring in stone masonry. However, their respective properties and characteristics dictate how and in which type of scenarios they might best be employed (Table 3).

In cases with significant contrast in the hygric properties of masonry units and mortar joints (e.g. granite units and lime mortar), microwave and radar provide similar information on the general distribution of water. Both techniques can provide 


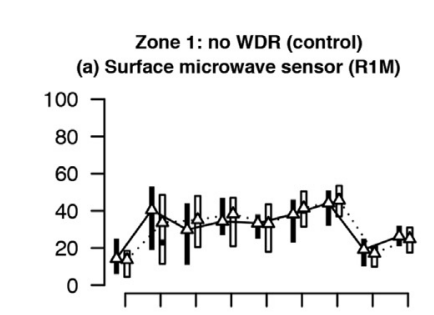

Zone 2: Heavy WDR, no joints

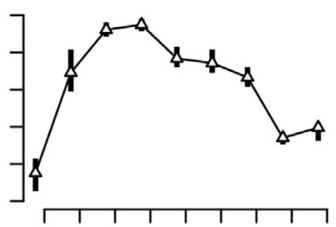

(b) Radar direct wave amplitude

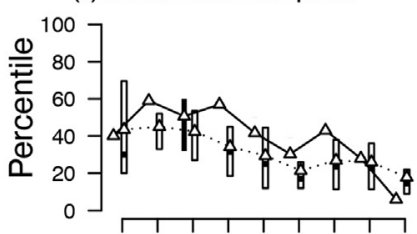

(c) Depth microwave sensor (PM)
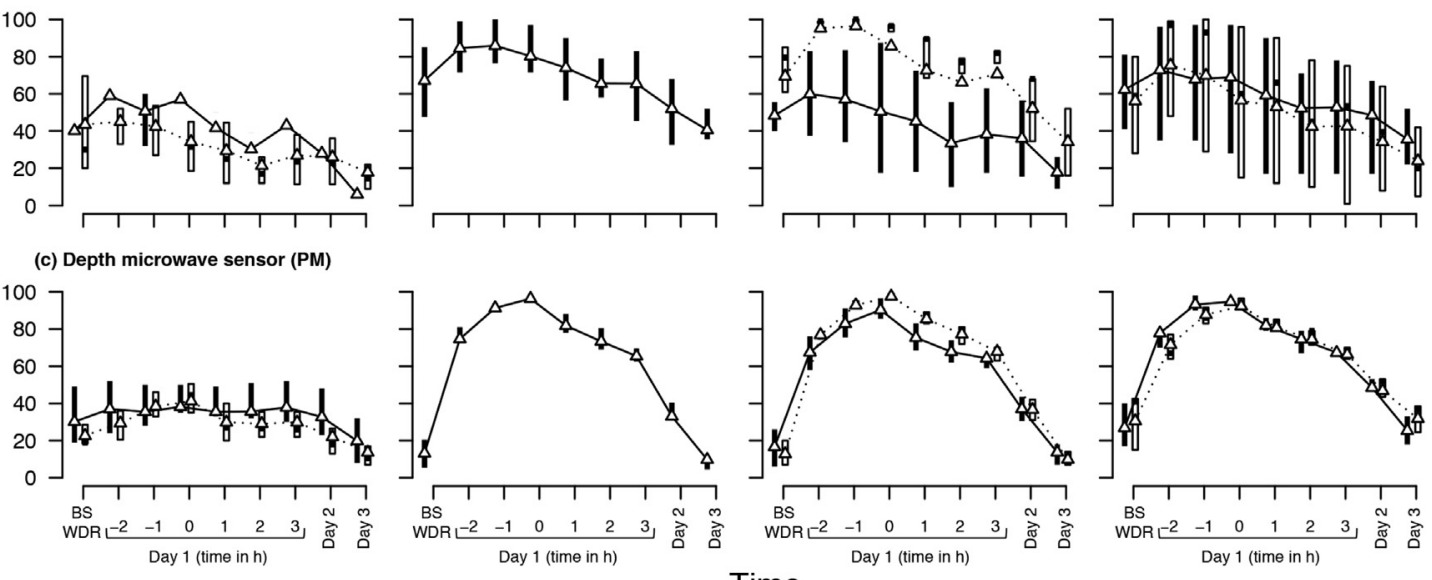

Zone 3: Heavy WDR, vertical and

horizontal joints
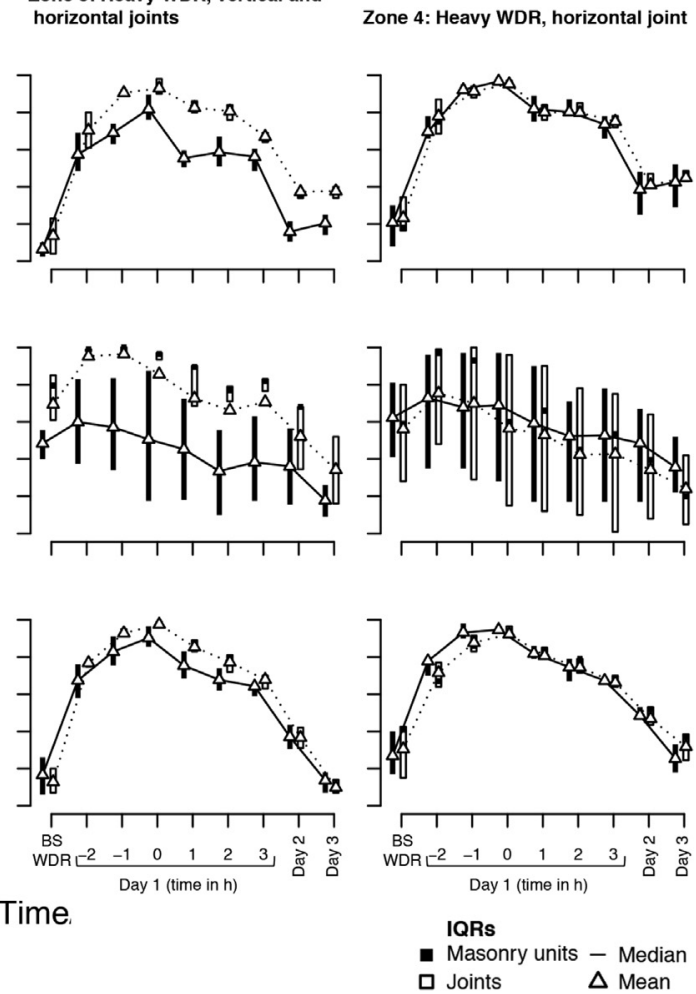

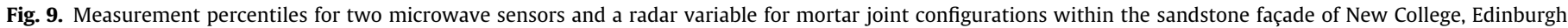

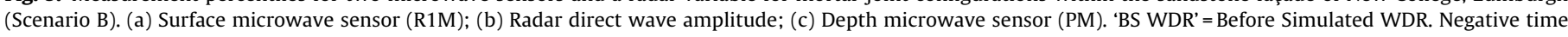
references represent hours within the spell ( $t=0$ is the beginning of the drying process).

Table 3

A summary of recommended techniques and variables to use for specific investigation objectives depending on the masonry scenario.

\begin{tabular}{|c|c|c|}
\hline Objective of investigation & $\begin{array}{l}\text { Contrasting hygric properties } \\
\text { of masonry units and mortar } \\
\text { joints }\end{array}$ & $\begin{array}{l}\text { Similar hygric properties of } \\
\text { masonry units and mortar } \\
\text { joints }\end{array}$ \\
\hline General distributions & Any (or in combination) & $\begin{array}{l}\text { Any microwave sensor (or in } \\
\text { combination) }\end{array}$ \\
\hline $\begin{array}{l}\text { Penetration through mortar } \\
\text { joints }\end{array}$ & Radar total travel time & Radar total travel time ${ }^{*}$ \\
\hline $\begin{array}{l}\text { Localised contents in masonry } \\
\text { stone units and mortar joints }\end{array}$ & Any (or in combination) & Radar direct wave amplitude \\
\hline Surface condensation & $\begin{array}{l}\text { Radar direct wave amplitude } \\
\text { or surface microwave sensor } \\
\text { (R1M) }\end{array}$ & $\begin{array}{l}\text { Radar direct wave amplitude } \\
\text { or surface microwave sensor } \\
\text { (R1M) }\end{array}$ \\
\hline
\end{tabular}

* Although not demonstrated here, this technique is applicable to various masonry configurations if the back wall can be detected at the operating frequency.

similar information on relative surface and depth moisture contents. Although the radar travel time can enable a streamlined analysis of water penetration through joints (and, average water contents across the depth of construction), a microwave depth sensor can provide slightly less useful (but still informative) output when the construction is too thick to produce a detectable back wall reflection.

The results of Scenario A of the Edinburgh experiment demonstrate that both radar and microwave techniques can be useful in evaluating the response of a construction with masonry units of higher sorptivity. The microwave sensor measurements provide uncomplicated information on relative levels of water content at a façade scale. This can be applied in an effective monitoring strategy in several ways:

1. to perform a rapid initial survey across a façade, site, or building, to characterise the overall distribution of moisture and support an exploration of potential moisture sources;
2. to undertake repeat measurements during a long-term (but periodic) monitoring exercise, which will be less influenced by recent and local environmental conditions, i.e. diurnal impact on measurements.

During the Edinburgh experiment the microwave measurements were taken with $10 \mathrm{~cm}$ point-spacing, while the radar was taken over a grid with $5 \mathrm{~cm}$ line spacing. Although this does introduce an additional variable into comparison of the microwave and radar methods, it acknowledges practical surveying considerations. The microwave measurements take longer time to collect, since the sensor head must be moved and placed in a new position prior to each reading (in this experiment, $9 \times 9=81$ measurements). In contrast, the radar antenna only need to be placed for each line (17 in each direction in this experiment) and it relatively easy to maintain alignment while collecting data along the transects. 
There are a several reasons why radar is an ineffective technique for surveying at a façade scale when the hygric properties of unit and joint within the masonry are similar:

- the radar data requires more post-processing to produce useful information;

- it is logistically less efficient than the handheld microwave sensor for rapidly collecting data in many areas (or across wide areas) of a façade or site;

- it exhibits greater influence from environmental conditions and localised surface conditions, especially with regard to surface condensation.

Radar can be used to evaluate the behaviour of masonry systems on a more localised scale than the façade or site. As demonstrated by Scenario B (and to a lesser extent the Oxford experiment), the radar measurements enable a discussion of how stone masonry functions as a system of units and joints functions. This has many potential applications, especially concerning decisions around retrofits and maintenance. For example, the analysis method used herein could be applied to evaluate the performance of original or repair mortar to inform whether repointing should be undertaken. It could also be used to evaluate the effectiveness of repointing after it has been implemented. As previously discussed, the radar travel time can also be used to identify regions where water has penetrated through joints, which is of particular use in scenarios in which only one-sided access is possible (and therefore visual inspection for water penetration is infeasible).

\subsection{Data visualisation and presentation}

The results of this study demonstrate that, in moisture monitoring with non-destructive electromagnetic sensors, a combination of spatial and temporal representations of measurements provides useful information. For example, identifying the transition between Stage I and Stage II drying is easily done with a temporal representation of measurements. However, using a spatial representation of radar travel times allows for the locations within a masonry system which experience water penetration through joints to be rapidly identified. The visual representation technique needs to support the objectives of the monitoring exercise to provide useful information.

The use of measurement percentiles in spatial representations supports more accurate interpretation of data than if colour bins were assigned to the original measurement data, since this data is rarely uniformly distributed. Using percentile representation in both heat map and bar plots facilitates comparison between them. This is not ideal if the measurements are subset into subgroups of significantly different sizes, as this can introduce skew. However, in a case where the measurements include a significant outlier or an erroneous value, the skew introduced when normalising or determining scales would outweigh that which is introduced by using percentile representation.

When using percentile representation, it is important not to assume that the 80th percentile in one technique is equivalent or comparable to the 80th percentile in another. As well, the 100th percentile (i.e. the maximum), is only the maximum of the survey measurements, and does not represent a saturated state. This could be addressed if samples of sufficient size of the relevant material(s) can be obtained. From this, oven-dry and saturated measurements could be determined for each material, which can be included in the measurement set prior to determining percentiles.

\section{Conclusion}

In this study, the response to simulated wind-driven rain spells of two types of stone masonry provided insight into how and when non-destructive electromagnetic sensors are best employed as part of a monitoring strategy:

- when the masonry units and mortar joints have significantly different hygric properties, both radar and microwave techniques provide useful information on the distribution;

- in more homogenous constructions, microwave sensors can provide useful information on the overall distribution of water across a façade, building, or site;

- radar measurements are more suited to investigate localised variation of water contents to evaluate the behaviour of masonry systems, and investigate surface water contents due to condensation;

- radar can also be used to identify areas in which water has penetrated through mortar joints to the interior of a construction;

- representing data in spatial and temporal visual forms facilitated a multi-perspective approach that enriched the interpretation of the monitoring;

- converting data into measurement percentiles improved the visual resolution of colour-based representations and reduced the impact of extreme outliers.

Both the evaluation of comparable advantages of moisturesensitive non-destructive techniques and methods of data manipulation and visual representation are important components of multidisciplinary management of built cultural heritage and warrant further development.

\section{Funding}

This work was supported by the UK Engineering and Physical Sciences Research Council (EPSRC) grant for the Centre for Doctoral Training in Science and Engineering in Arts, Heritage and Archaeology (EP/L016036/1). We also acknowledge the financial support from Historic England, Historic Environment Scotland and the Natural Sciences and Engineering Research Council of Canada (PGSD3-471105-2015).

\section{Acknowledgements}

We are grateful for the logistical support provided by Land Engineering and the Consarc Design Group for the site-based experiments in Edinburgh. We would also like to thank William Revie and Colin Burns for constructing the granite test wall.

\section{Appendix A. Supplementary data}

Supplementary data associated with this article can be found, in the online version, at https://doi.org/10.1016/j.culher.2019.07.011.

\section{Références}

[1] C. Almeida, J.P. Guedes, A. Arêde, C. Costa, A. Costa, Physical characterization and compression tests of one leaf stone masonry walls, Constr. Build. Mater. 30 (2012) 188-197.

[2] V. Bosiljkov, M. Uranjek, R. Žarnić, V. Bokan-Bosiljkov, An integrated diagnostic approach for the assessment of historic masonry structures, J. Cult. Herit. 11 (3) (2010) 239-249.

[3] E. Lucchi, Thermal transmittance of historical stone masonries: a comparison among standard, calculated and measured data, Energy Build. 151 (2017) 393-405.

[4] C. Hall, A. Hamilton, W.D. Hoff, H.A. Viles, J.A. Eklund, Moisture dynamics in walls: response to micro-environment and climate change, Proc. 
R. Soc. Lond. A: Math. Phys. Eng. Sci. 467 (2125) (2011) 194-211, http://dx.doi.org/10.1098/rspa.2010.0131.

[5] C. Sabbioni, P. Brimblecombe, M. Cassar, The Atlas of Climate Change Impact on European Cultural Heritage: Scientific Analysis and Management Strategies, Anthem Atlas and Reference Series, Anthem, 2010

[6] S.A. Orr, M. Young, D. Stelfox, J. Curran, H. Viles, Wind-driven rain and future risk to built heritage in the united kingdom: novel metrics for characterising rain spells, Sci. Total Environ. 640-641 (2018) 1098-1111, http://dx.doi.org/10.1016/j.scitotenv.2018.05.354.

[7] E. Rirsch, Z. Zhang, Rising damp in masonry walls and the importance of mortar properties, Constr. Build. Mater. 24 (10) (2010) 1815-1820.

[8] D. D'Ayala, Y.D. Aktas, Moisture dynamics in the masonry fabric of historic buildings subjected to wind-driven rain and flooding, Build. Environ. 104 (2016) 208-220, http://dx.doi.org/10.1016/j.buildenv.2016.05.015.

[9] T. Sun, K.T. Grattan, S. Srinivasan, P. Basheer, B.J. Smith, H.A. Viles, Building stone condition monitoring using specially designed compensated optical fiber humidity sensors, IEEE Sens. J. 12 (5) (2011) 1011-1017.

[10] E.A. Laycock, C. Wood, Understanding and controlling the ingress of driven rain through exposed, solid wall masonry structures, Geol. Soc. Lond. Spec. Publ. 391 (1) (2014) 175-191.

[11] L. Palaia, R. Sánchez, V. López, L. Gil J. Monfort, S. Tormo, P. Navarro, M. Álvarez, Procedure for ndt and traditional methods of ancient building diagnosis by using thermograph, digital images and other instruments data analysis, in: 17th World Conference on Nondestructive Testing, Shangai, China, 2008, pp. 25-28.

[12] C. Groot, J. Gunneweg. The influence of materials characteristics and workmanship on rain penetration in historic fired clay brick masonry, Heron 55 (2) (2010).

[13] E. Lucchi, F. Roberti, T. Alexandra, Definition of an experimental procedure with the hot box method for the thermal performance evaluation of inhomogeneous walls, Energy Build. 179 (2018) 99-111.

[14] E. Barreira, R.M. Almeida, J. Delgado, Infrared thermography for assessing moisture related phenomena in building components, Constr. Build. Mater. 110 (2016) 251-269

[15] L.R. Valero, V.F. Sasso, E.P. Vicioso, In situ assessment of superficial moisture condition in façades of historic building using non-destructive techniques, Case Stud. Constr. Mater. 10 (2019) e00228.

[16] J. Válek, S. Kruschwitz, J. Wöstmann, T. Kind, J. Valach, C. Köpp, J. Lesák, Nondestructive investigation of wet building material: multimethodical approach, J. Perform. Constr. Facil. 24 (5) (2010) 462-472.

[17] M. Martínez-Garrido, R. Fort, M. Gómez-Heras, J. Valles-Iriso, M. Varas-Muriel, A comprehensive study for moisture control in cultural heritage using nondestructive techniques, J. Appl. Geophys. 155 (2018) 36-52.

[18] S. Laurens, J. Balayssac, J. Rhazi, G. Klysz, G. Arliguie, Non-destructive evaluation of concrete moisture by gpr: experimental study and direct modeling, Mater. Struct. 38 (9) (2005) 827-832

[19] G. Klysz J.-P. Balayssac, Determination of volumetric water content of concrete using ground-penetrating radar, Cement Concr. Res. 37 (8) (2007) 1164-1171, http://dx.doi.org/10.1016/j.cemconres.2007.04.010.

[20] D. Camuffo, Standardization activity in the evaluation of moisture content, J. Cult. Herit. 31 (2018) S10-S14, http://dx.doi.org/10.1016/j.culher.2018.03.021.

[21] L. Nilsson, Methods of Measuring Moisture in Building Materials and Structures: State-of-the-Art Report of the RILEM Technical Committee 248-MMB, RILEM State-of-the-Art Reports, Springer International Publishing, 2018.

[22] E. Rosina, A. Sansonetti, N. Ludwig (Eds.), MODIHMA 2018 innovative techniques for MOisture Detection in HIstorical MAsonry, J. Cult. Herit. 31 (Supplement) (2018) S1-S88.

[23] S.E. Pinchin, in: Techniques for monitoring moisture in walls, Stud. Conserv. 53 (S-2) (2008) 33-45, http://dx.doi.org/10.1179/sic.2008.53.Supplement-2.33.

[24] O. Sass, H. Viles, in: Wetting and drying of masonry walls: 2Dresistivity monitoring of driving rain experiments on historic stonework in Oxford, UK, J. Appl. Geophys. 70 (1) (2010) 72-83, http://dx.doi.org/10.1016/j.jappgeo.2009.11.006.

[25] O. Sass, H. Viles, in: Two-dimensional resistivity surveys of the moisture content of historic limestone walls in Oxford, UK: implications for understanding catastrophic stone deterioration, Geol. Soc. Spec. Publ. 331 (2010) 237-249, http://dx.doi.org/10.1144/SP331.22.

[26] M. Martínez-Garrido, R. Fort, M. Gómez-Heras, J. Valles-Iriso, M. VarasMuriel, in: A comprehensive study for moisture control in cultural heritage using non-destructive techniques, J. Appl. Geophys. 155 (2018) 36-52, http://dx.doi.org/10.1016/j.jappgeo.2018.03.008.

[27] S. Orr, M. Young, D. Stelfox, A. Leslie, J. Curran, H. Viles, in: An 'isolated diffusion' gravimetric calibration procedure for radar and microwave moisture measurement in porous building stone, J. Appl. Geophys. 163 (2019) 1-12, http://dx.doi.org/10.1016/j.jappgeo.2019.02.003.
[28] ISO, ISO 15927-3: 2009: Hygrothermal Performance of Buildings - Calculation and Presentation of Climatic Data - Part 3: Calculation of a Driving Rain Index for Vertical Surfaces From Hourly Wind and Rain Data, Standard, International Standards Organisation, 2009

[29] UK Met Office, MIDAS: UK Hourly Weather Observation Data, 2006.

[30] UK Met Office, MIDAS: UK Hourly Rainfall Data, 2006

[31] L. Fusade, S. Orr, C. Wood, M. O'Dowd, H. Viles, in: Drying out traditional masonry - response of lime-mortar joints in granite test walls after an intense rainfall, before and after repointing, Herit. Sci. (2019).

[32] B. Blocken, G. Dezsö, J. van Beeck, J. Carmeliet, in: Comparison of calculation models for wind-driven rain deposition on building facades, Atmos. Environ. 44 (14) (2010) 1714-1725

[33] P. Briggen, B. Blocken, H. Schellen, in: Wind-driven rain on the facade of a monumental tower: numerical simulation, full-scale validation and sensitivity analysis, Build. Environ. 44 (8) (2009) 1675-1690.

[34] S.A. Orr, H. Viles, in: Characterisation of building exposure to wind-driven rain in the UK and evaluation of current standards, J. Wind Eng. Ind. Aerodyn. 180 (2018) 88-97, http://dx.doi.org/10.1016/j.jweia.2018.07.013.

[35] J.M. Pérez-Bella, J. Domínguez-Hernández, B. Rodríguez-Soria, J.J. del Coz-Díaz, E. Cano-Su nén, in: Estimation of the exposure of buildings to driving rain in Spain from daily wind and rain data, Build. Environ. 57 (2012) 259-270, http://dx.doi.org/10.1016/j.buildenv.2012.05.010.

[36] L. Fusade, S.A. Orr, C. Wood, M. O'Dowd, H. Viles, in: Drying response of limemortar joints in granite masonry after an intense rainfall and after repointing Herit. Sci. 7 (1) (2019) 38.

[37] S.J. Brown, The disruption and the dream: the making of New College, 1843-1861, in: G.D. Wright, D.F. Badcock (Eds.), Disruption to Diversity: Edinburgh Divinity 1846-1996, T\&T Clark, 1996, pp. 29-50.

[38] G. Craig, in: On building stones used in Edinburgh: their geological sources, relative durability and other characteristics, Trans. Edinb. Geol. Soc. 6 (4)(1892) 254-273.

[39] Jowa Environmental Mesonet, Wind Roses for Edinburgh Airport [online], 2018, Electronic [cited 15.07.18]

[40] A. Göller, Microwave scanning technology for material testing, in: Proceedings of the 9th European Conference on NDT, DGZfP-Proceedings BB, 2006.

[41] A. Göller, MOIST SCAN - multilayer microwave moisture scans at buildings, masonry and civil structures, in: Proceedings of the 14th International Conference and Exhibition on Structural Faults and Repair, Edinburgh, 2012

[42] W.W.-L. Lai, X. Dérobert, P. Annan, in: A review of Ground Penetrating Radar application in civil engineering: a 30-year journey from locating and testing to imaging and diagnosis, NDT \& E Int. 96 (2018) 58-78, http://dx.doi.org/10.1016/j.ndteint.2017.04.002.

[43] D. Camuffo, C. Bertolin, in: Towards standardisation of moisture content measurement in cultural heritage materials, E-Preserv. Sci. 9 (2012) 23-35.

[44] W.W.-L. Lai, T. Kind, S. Kruschwitz, J. Wöstmann, H. Wiggenhauser, in: Spectral absorption of spatial and temporal ground penetrating radar signals by water in construction materials, NDT \& E Int. 67 (2014) 55-63, http://dx.doi.org/10.1016/j.ndteint.2014.06.009.

[45] C.M. Carswell, in: Choosing specifiers: an evaluation of the basic tasks model of graphical perception, Hum. Factors 34 (5) (1992) 535-554, http://dx.doi.org/10.1177/001872089203400503.

[46] W.S. Cleveland, R. McGill, in: Graphical perception and graphical methods for analyzing scientific data, Science 229 (4716) (1985) 828-833, http://dx.doi.org/10.1126/science.229.4716.828.

[47] S.N. Friel, F.R. Curcio, G.W. Bright, in: Making sense of graphs: critical factors influencing comprehension and instructional implications, J. Res. Math. Educ. (2001) 124-158, http://dx.doi.org/10.2307/749671.

[48] C. Völker, P. Shokouhi, in: Multi sensor data fusion approach for automatic honeycomb detection in concrete, NDT \& E Int. 71 (2015) 54-60 http://dx.doi.org/10.1016/j.ndteint.2015.01.003.

[49] G.W. Scherer, in: Theory of drying, J. Am. Ceram. Soc. 73 (1) (1990) 3-14, http://dx.doi.org/10.1111/j.1151-2916.1990.tb05082.x.

[50] L.F. Cooling, in: The evaporation of water from brick, Trans. Ceram. Soc. 29 (1930) 39-54.

[51] J. van Brakel, in: Mass transfer in convective drying, Adv. Dry. 1 (1980) 217-267.

[52] C. Hall, W. Hoff, Water Transport in Brick, Stone and Concrete, 2nd Ed., Spon Press, Taylor \& Francis Group, London, New York, 2012.

[53] E. Vereecken, S. Roels, in: Hygric performance of a massive masonry wall: how do the mortar joints influence the moisture flux?, Constr. Build. Mater 41 (2013) 697-707, http://dx.doi.org/10.1016/j.conbuildmat.2012.12.024.

[54] Z.M. Sbartaï, S. Laurens, J. Rhazi, J.P. Balayssac, G. Arliguie, in: Using radar direct wave for concrete condition assessment: correlation with electrical resistivity, J. Appl. Geophys. 62 (4) (2007) 361-374, http://dx.doi.org/10.1016/j.jappgeo.2007.02.003. 